\title{
A perceptual isolation effect in
}

\section{short-term memory ${ }^{1}$}

WILLIAM E. GUMENIK and FAY ROSSMAN, University of Toledo, Toledo, Ohio 43606

Perceptually isolating a CCC by enclosing it in a rectangle improved STM for that item. No residual effects of this isolation were found on following nonisolated items. The possibility of accounting for improved STM of items involving conceptual class change in terms of enhancement through isolation, instead of reduction of semantic interference effects of previous items, was discussed.

Several investigators have reported better STM for items differing in conceptual class from previously presented items than for items that did not. Several kinds of conceptual class changes have been used, e.g., from $\mathrm{CCC}$ s to triads of words (Wickens \& Ekler, 1968), from three-digit numbers to triads of words (Wickens \& Simpson, 1968), and from words in one denotative category to words in another denotative category (Loess, 1968).

Wickens has termed the facilitative effect of class change on STM as release of proactive interference. Wickens and Loess interpreted the facilitation of STM for items following class change in terms of reduction of semantic interference effects from previous items. While this interpretation appears reasonable, it is difficult to reconcile with the findings in several studies of little or no interference effects of semantic factors on STM (e.g., Baddeley, 1964; Baddeley, 1966; Gumenik, 1969).

Another possible explanation of the facilitative effects of class change on STM, mentioned by Loess (1968, p. 92), is a "von Restorff-like perceptual enchancement" of the stimulus. It appears reasonable that a sudden change in the class of an item should result in increased attention to that item which may affect its STM. If this explanation is tenable, then increasing the saliency of an item by a means other than conceptual class change, such as perceptual isolation, should improve STM for that item. The present experiment investigated the effect of perceptual isolation of an item on its STM.

Fig. 1. Mean number of letters recalled in their correct position on successive trials with different $\mathrm{CCCs}$.

\section{SUBJECTS}

The Ss were 202 introductory psychology students who participated as part of a course requirement. They were assigned randomly to experimental and control groups, each consisting of $101 \mathrm{Ss}$. MATERIALS AND APPARATUS

The stimuli were $12 \mathrm{CCCs}$, having $17 \%$ Witmer association values (Underwood \& Shulz, 1960, pp. 318-329): ZLQ, HFM, CWH, QXG, SGJ, DJS, BMF, JHW, GKZ, XDL, TZX, KBP.

The CCCs were typewritten in elite type, printed on slides, and projected by a Sawyer slide projector, Model 550R, on a screen 70 in. away. S sat approximately the same distance from the screen. The projected dimensions of the slides were $16 \mathrm{in}$. in height and $22 \mathrm{in}$. in length. The projected dimensions of the $\mathrm{CCCs}$, which were centered on the slides, were $1-5 / 8$ in in height and 6-3/4 in. in length. In the case of isolated items, a rectangle, consisting of a line $1 / 2$ in. thick, 3 in. distant from the top, bottom, and sides of the $\mathrm{CCC}$, enclosed the CCC.

Time intervals were controlled by Hunter timers, Model $111 \mathrm{C}$.

\section{PROCEDURE}

Each $S$ was tested individually. A CCC that $S$ was to read silently was presented on the screen for $1 \mathrm{sec}$. The screen then went dark and $S$ was orally given a three-digit number, from which $S$ was to count backward by threes aloud, without repeating the number. as rapidly and accurately as possible. This delay period consisted of $9 \mathrm{sec}$. The screen was then lit. signaling a 2 -sec recall period. during which time the $\mathrm{S}$ recalled the $\mathrm{CCC}$ aloud. After this, following the .3 -sec slide change, the next CCC was presented for $1 \mathrm{sec}$.

Each $S$ had 12 trials, a different CCC being presented on each trial. The order of the CCCs was randomized for each S.

Treatment of the experimental and control Ss differed only in that for experimental $S$ s the ninth trial differed from preceding and following trials by the $\mathrm{CCC}$ being enclosed in a rectangle.

\section{RESULTS}

The measure of STM used was the number of letters remembered in their correct positions in the CCC. This measure could range from 0 to 3 . Means of this measure for the experimental and control groups are plotted for the 12 STM trials in Fig. 1.

The data were analyzed in three portions. On Trials 1 through 8 , experimental and control groups received the same treatment. Examination of these trials in Fig. 1 shows a rapid decline in STM for both groups reaching asymptote at the third trial and that the two groups were equivalent during these trials. ANOVA indicated a significant trials effect, $F(7,1400)=26.29, p<.01$, and no significant groups effect or Groups by Trials interaction, $F<1$ in both cases.

Trial 9, in which the CCC was perceptually isolated by being enclosed in a rectangle, for the experimental group but not for the control group, was of major interest. Examination of Fig. 1 reveals better STM for the experimental than for

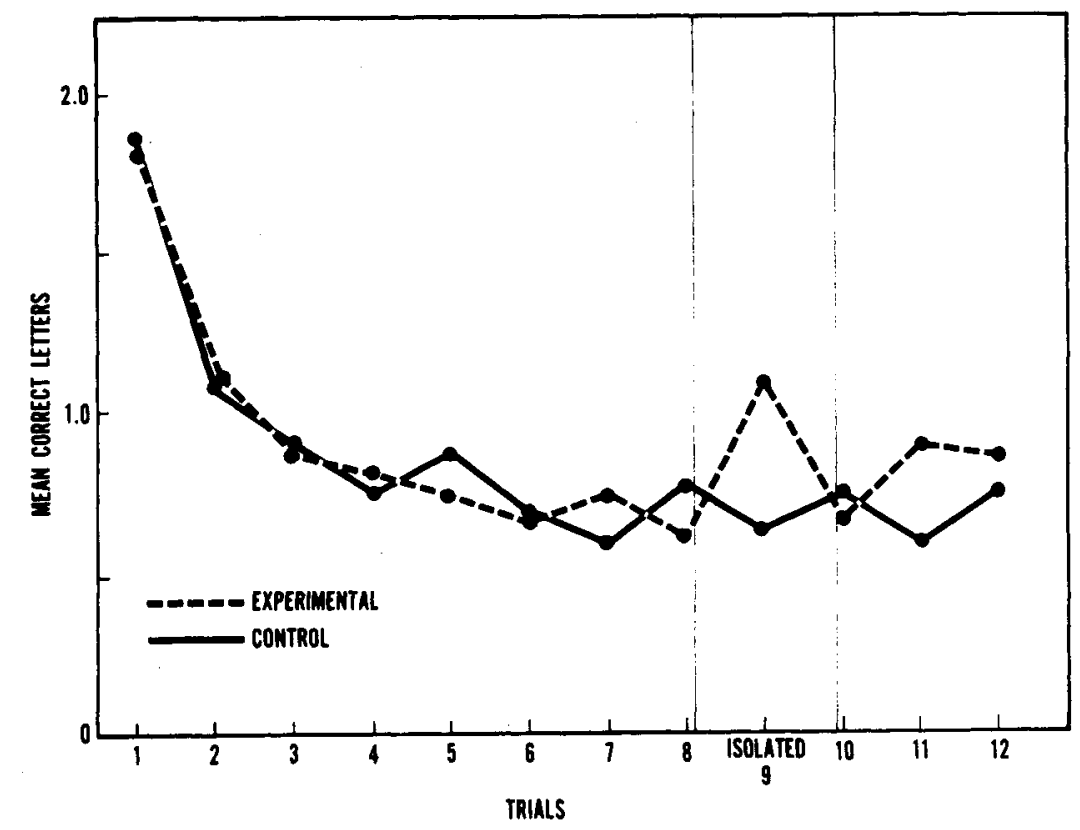


the control group on this trial. This isolation effect was significant, $\mathrm{t}(200)=3.02, \mathrm{p}<.01$.

While treatments were again the same for experimental and control groups on the post-isolation trials, 10 through 12 , these trials were analyzed to determine if there were any residual effects from the previous isolation. Though from examination of Fig. 1, one might consider the experimental group to have slightly better STM on Trial 11 than the control group, ANOVA on the three post-isolation trials indicated that the groups and trials effects as well as their interaction were not significant, $p>.10$ in all three cases. Therefore, any apparent differences on post-isolation trials were attributed to chance factors.

When a more lenient criterion of STM, number of correct letters irrespective of their positions, was used, similar results were obtained throughout.

\section{DISCUSSION}

The results of the present experiment demonstrate that perceptually isolating an item increases its STM. Turvey \& Egan (1969), in a similar experiment, using slide area as the means of perceptual isolation, a $10-\mathrm{sec}$ recall period, and no post-isolation trials, also found improved STM for perceptually isolated items, lending further support for the present finding. Unfortunately, Turvey and Egan's measure of STM is questionable. A score of 2 was given to each letter of the $\mathrm{CCC}$ in its correct position and a score of 1 to each correct letter in an incorrect position. This assumes equivalence between one letter in its correct position (score $=2$ ) and two letters in incorrect positions ( assumption that would be difficult to justify. Furthermore, while this measure allows scores ranging from 0 to 6 , a score of 5 is impossible, raising some question about the scale.

Increasing the saliency of an item through perceptual isolation facilitates STM of that item. It is possible that better STM of an item involving a sudden change in conceptual class might also be attributable to increased attention to that item, rather than to a reduction of semantic interference effects from previous items. If this were the case, the findings of improved STM for an item differing in conceptual class from previously presented items (e.g., Loess, 1968; Wickens \& Ekler, 1968; Wickens \& Simpson, 1968) could easily be reconciled with findings of little or no semantic interference effects in STM (e.g., Baddeley, 1964; Baddeley, 1966: Gumenik, 1969).

A further finding of the present experiment was that there was no significant differences of isolating an item on the STM of post-isolation items. This may be analogous to the failure of several, but not all, investigators to find effects of stimulus isolation on non-isolated items (e.g., Gumenik \& Levitt, 1968).

The present STM task differed greatly from the usual serial or paired-associate learning situation in which isolation effects are found in that the present task did not involve repetition of the same items over several trials. Also, the present STM task involved the discrete recall of individual items rather than the learning of an entire list of items simultaneously. However, the similarity of isolation effects in the present STM task and in serial and paired-associate learning suggest that the same mechanism may be involved. One possible mechanism that might be operating in these disparate tasks could be akin to the "attention-getting value" of the isolated item suggested by Green (1958), which might enhance both STM of the item and the learning of the item in the repeated trials of a serial or paired-associate task.

\section{REFERENCES}

BADDELEY, A. D. Semantic and acoustic similarity in short-term memory. Nature, 1964. 204, 1116-1117.

BADDELEY, A. D. Short-term memory for word sequences as a function of acoustic, semantic and formal similarity. Quarterly Journal of Experimental Psychology, 1966, 18, 362-365. GRFEN, R. T. The attention-getting value of structural change. British Journal of Psychology, 1958,49,311-314.

GLMENIK. W. E. Effects of articulatory activity and auditory, visual and semantic similarity on the short-term memory of visually presented paired associates. Journal of Experimental Psychology. 1969, 82, 70-74.

GUMENIK, W. E., \& LEVITT, J. The von Restorff effect as a function of difference of the isolated item. American Journal of Psychology, 1968, 81, 247-252.

LOESS, H. Short-term memory and item similarity. Journal of Verbal Learning \& Verbal Behavior, 1968, 7, 87-92.

TURVEY. M. T., \& EGAN, J. Contextual change and release from proactive interference in short-term verbal memory. Joumal of Experimental Psychology, 1969, 81, 396-397.

UNDERWOOD, B. J., \& SCHULZ, R. W. Meaningfulness and verbal learning. Chicago: Lippincott, 1960.

WICKENS, D. C., \& EKLER, M. R. Semantic as opposed to acoustic encoding in STM. Psychonomic Science, 1968, 12,63.

WICKENS, D. D., \& SIMPSON, H. K. Semantic vs. phonetic encoding in short term memory. Paper presented at the meeting of the Midwestern Psychological Association, St. Louis, 1968

1. The authors wish to thank Patricia Mundelius for her assistance in computing the data.

\section{Age changes in the Poggendorff illusion as measured by a method of production}

\section{A. W. PRESSEY $Y^{l}$ and O. SWEENEY, University of Manitoba, Winnipeg 19, Canada}

Children at three age levels were tested on the Poggendorff illusion with a method of production. The illusion decreased with age; this supports previous investigations in which the method of adjustment was used. A sex difference of marginal significance was found, but the illusion did not change as a function of successive trials. It was concluded that the method of production is a valid means of measuring the Poggendorff illusion.

If two portions of a single oblique line are interrupted by two separate parallel lines, the two obliques do not appear collinear. Such a configuration is known as the Poggendorff illusion and is illustrated in Fig. $1 \mathrm{~A}$.

Traditionally, the method of adjustment has been employed to measure the illusion, but recently a method of production has been employed (Pressey \& Sweeney, 1969). Here, one of the obliques is removed, as shown in Fig. 1B, and $S$ is required to place a dot on the right vertical line so that the oblique on the left appears to point to it. There are several advantages to the method of production. First, complex, bulky and expensive equipment is not required. Second, the time necessary to test a $S$ is greatly reduced, and finally, the production method might easily lend itself to group testing. The major question

A

B

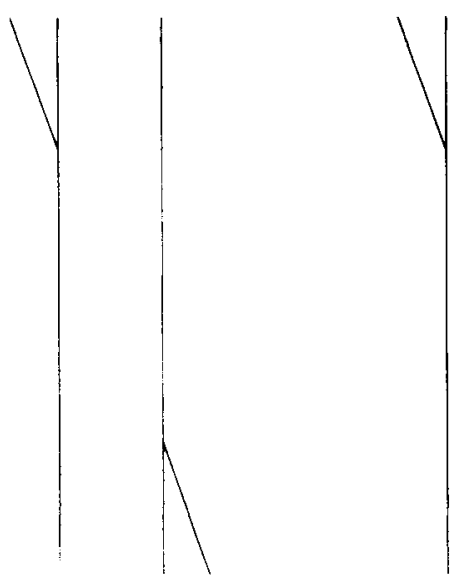

Fig. 1. The classical version (A) and a variation-(B) of the Poggendorff illusion. 